\title{
Dynamic Cervical Implant (DCI) In Single Level Cervical Disc Disease
}

\author{
Mohamed M. Mohi Eldin*
}

Department of Neurosurgery, Faculty of Medicine, Cairo University, Egypt

\begin{abstract}
Introduction: This study evaluated the safety and effectiveness of Dynamic Cervical Implants (DCI) as a form of dynamic instrumentation to treat single level cervical disc disease. This is a prospective case study of 15 consecutive patients, treated by the author, with single level cervical disc disease. Study duration was 3 years from October 2009 to October 2012. These 15 cases included 10 men and 5 women. Patient's ages ranged from 35 to 54 years (mean, 47 years). All patients had anterior cervical discectomy with interbody DCI implantation, at a single level from C3 to C7. Placement of the DCI implant aimed at reconstruction of the anterior column to preserve a controlled flexion and extension motion.
\end{abstract}

Materials and Methods: Among the 15 cases, herniated cervical disc (HCD) accounted for 7 and cervical degenerative disc disease (DDD) for 8 . Neck pain was present in all cases, radiculopathy in 9 cases, radiculomyelopathy in 4 cases and myelopathy in 2 cases. Preoperative evaluation included plain cervical x-rays including dynamic views. Magnetic resonance imaging (MRI) was carried out routinely to confirm the clinical diagnosis.

Results: Our study showed that the procedure was safe and easy. There were no major complications. The most common DCI prosthesis used in this study was the $6 \mathrm{M}$ size with a width of $12 \mathrm{~mm}$, a depth of $12 \mathrm{~mm}$, and a height of $9 \mathrm{~mm}$. No implant related complications were reported. This procedure has the advantages of shorter operative time; minimal blood loss; and early postoperative recovery. Neck pain and radiculopathy improved in $86.7 \%$ of cases, and myelopathy in $50 \%$ of cases. Hetertopic ossification indicating fusion was not observed.

Conclusion: Disc replacement with DCI is a new strategy, in between ACDF \& ADR. It is an intermediate solution in the spectrum of management strategies of cervical disc diseases. Immediate dynamic stability with good clinical response and no implant-related morbidity or complications are the main advantages of this implant.

Keywords: Dynamic, cervical, implant, DCI, anterior fusion, cervical disc disease.

\section{INTRODUCTION}

The concept of a degenerative disc as a pain generator has gradually been accepted [1-4]. Many studies reported successful results and the advantages of using interbody fusions in the treatment of cervical disc disorders [4-6]. Therefore, interbody implant insertion follo-wing discectomy for cervical degenerative disc disease (DDD) and herniated cervical disc (HCD) to maintain sufficient disc height and neuroforamen volume to support the anterior column has become an indicated and important step [7]. The aim of most new cervical interbody implants is to maintain or restore function. If the interbody implant can maintain a controlled movement in the affected motion segment, i.e. restoring function, results are supposed to be better than static fusions and adjacent level disease (ALD) secondary to fusions is supposed to be delayed.

In the spectrum of anterior cervical fusion techniques comes the dynamic cervical implant (DCI) in the middle of the spectrum between static fusions and cervical total disc

*Address correspondence to this author at the Department of Neurosurgery, Faculty of Medicine, Cairo University, Egypt; Tel: 00201227342964;

E-mails:mmohi63@yahoo.com,mmohi63@hotmail.com replacements (TDR), offering a relatively wide range of indications to the surgeon. Limitations to the use of TDR are restricted indications, fusion, overdistraction, and designrelated complications. In contrast to TDR, the DCI implant protects the facet joints while controlling axial rotation. The DCI implant offers stable, controlled (adequate) motion to the treated motion segment. In addition, the implant's axial compliance offers dampening capabilities. Thus, it avoids overloading and accelerated degeneration of the adjacent segments above and below the treated segment.

The DCI is a titanium implant, originally developed in 2002 by Dr. Guy Matgé, Luxembourg. It was introduced in clinical use, by him, in 2004. The design was further optimized to better accommodate the implant to the anatomy. In that second generation the footprint was changed from square to rectangular and more sizes were added. The DCI implant, with motion preservation, is more than a static cage. It stabilizes the cervical spine while still providing stable, limited, controlled flexion and extension motion allowing the spine to be functionally dynamic. It also works as a shock absorber, preventing accelerated degeneration in adjacent segments $[8,9]$. Thus, the DCI implant aims at combining the advantages of the gold standard "Fusion" with a motion preservation philosophy. The DCI has much greater indications than conventional static fusions \& even TDR, because 
of the controlled rotation. Thus, degenerative arthropathy remains an indication of DCI insertion.

The purpose of this preliminary study was to assess safety and effectiveness of Dynamic Cervical Implants (DCI) as a form of dynamic fusion to treat single level cervical disc disease. Clinical and radiologic outcomes were studied to evaluate the DCI implant ability to maintain dynamic motion, thus avoiding adjacent segment degen-eration.

\section{MATERIALS AND METHODS}

\section{Patient Selection}

This is a prospective case study of 15 consecutive patients, treated by the author, with single level cervical disc disease. Study duration was 3 years from October 2009 to October 2012. These 15 cases included $10 \mathrm{men}$ and 5 women. Patient's ages ranged from 35 to 54 years (mean, 47 years). All patients had anterior cervical discectomy with interbody DCI implantation, at a single level from C3 to C7. Placement of the DCI implant aimed with reconstruction of the anterior column to preserve a controlled flexion and extension motion.

The indications for DCI implantation in this study (Fig. 2) included: cervical DDD and/or HCD with discogenic neck pain, arm/shoulder radiating pain, or myelopathy; and involvement of discs between $\mathrm{C} 3$ and $\mathrm{C} 7$ at one level. Although multilevel implantation can be done, we only used a single-level procedure in this study. All cases should have at least 12 weeks of failed conservative management. Conservative treatment consisted of bed rest, physical therapy, muscle relaxants and anti-inflammatory drugs. The only exceptions were cases with incapacitating pain and refractory to the medical treatment or cases with motor affection. The persistence of neck pain, radicular pain or the presence of progressive neurological deficits was the main stay for inclusion into the study.

Inclusion criteria included single-level, mobile, cervical segment with cervical disc disease from $\mathrm{C} 3$ to $\mathrm{C} 7$; including disc herniation, degenerative discopathy and discogenic stenosis. Adjacent level protection above or below an already fused level is the best indication for DCI implantation. DCI has much larger indications than conventional disc prosthesis because of controlled rotation: therefore degenerative arthropathy, remains an indication for the DCI implant contrary to most disc arthroplasties.

Severe mechanical instability, absence of motion at the affected level, osteoporosis, fractures, infections and tumors are clear contraindications for DCI. Preoperative dynamic views as well as MRI are systematically performed in all cases to avoid these pitfalls.

Among the 15 cases, HCD accounted for 7 and DDD for 8. Neck pain was present in all cases, radiculopathy in 9 cases, radiculomyelopathy in 4 cases and myelopathy in 2 cases. Preoperative evaluation included plain cervical x-rays including dynamic views. Magnetic resonance imaging (MRI) was carried out routinely to confirm the clinical diagnosis.

\section{THE DCI IMPLANT}

The DCI implant used in this study has a unique design. The omega shape was designed to fit to the lateral anatomical view of the disc and the adjacent endplates. It is a one piece anatomical-shaped, self-fixing dynamic spacer made of titanium, easy to implant like a cage (Fig. 4 and 5). Being a single-piece implant, it has excellent fatigue strength with no wear debris. The implant auto-stabilize itself by engaging the anteriorly-placed teeth of the implant in the endplates of the vertebra above \& below. The Dynamic Cervical Implant stabilizes the cervical spine while providing controlled motion in flexion-extension which is the main motion in subaxial cervical spine. Shock absorption, a main advantage compared to most existing prostheses, prevents adjacent accelerated degeneration. The new design with a rectangular shape and sharper teeth optimized the primary stability of the implant.

\section{THE DCI SURGICAL TECHNIQUE}

Patient positioning and surgical approach are standard as in microsurgical anterior cervical discectomy and fusion (ACDF) using CASPAR vertebral distractors. Microdiscectomy was performed, leaving a clean disc space. Endplate cleaning is careful to respect cartilage and avoid bony bleeding. It is recommended not to remove anterior osteophytes preventing heterotopic ossification. Internal foraminotomy is an important step in radiculopathy cases together with posterior longitudinal ligament (PLL) resection for optimal decompression in myelopathy cases. With three trial/implant sizes and four different footprints, there is a selection of twelve implant sizes covering almost every patient. Trial implants are then utilized to define the appropriate implant size. Exact size selection is most important to avoid migration. The general guideline for optimal implant sizing is selecting the implant with the maximum width and a proper height as needed for appropriate restoration of the segment. The trial is centered at the midline of the medial-lateral diameter of the vertebral body. Implant positioning is centered at midline with maximum endplate coverage for optimal stress distribution, and in an attempt to keep physiologic lordosis as possible. The implant is inserted utilizing the DCI inserter for protection of endplate surface due to reduced implant height during insertion and the use of depth stop for accurate positioning. By the use of the depth stop an optimal insertion depth of $2-3 \mathrm{~mm}$ inside the anterior and posterior border can be measured. This is verified under fluoroscopic control (see picture below). The depth stop of the insertion instrument is adjusted to the depth measured on the trial implant. In the lateral view, a security zone of $2-3 \mathrm{~mm}$ to the anterior and posterior vertebral border should be respected. It is important to place the implant as far as posterior to fit the concavity of the inferior endplate of the superior vertebral body. The trials with depth control facilitate ideal positioning. Slight compression on CASPAR distractor stabilizes further the implant by engaging teeth in the endplates. In cases of heavy patients, short neck, or bad fluoroscopic controls, you may check the dural plane/DCI with a small nerve hook under microscope (Fig. 1 and $\mathbf{6}$ ). 

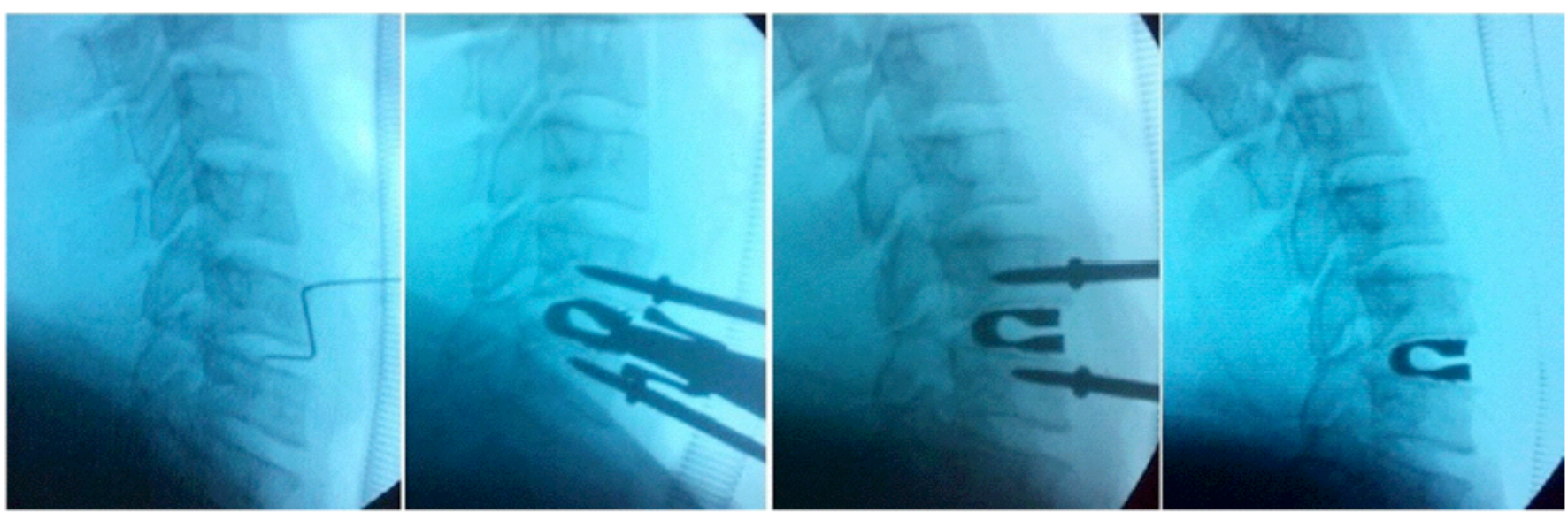

Fig. (1). Intraoperative fluoroscopic images showing level localization, application of DCI with Casper retractor in place, and final position of the implant.

\section{FOLLOW-UP EVALUATION AND OUTCOME MEASURES}

Operative time, blood loss, hospital stay, and the complications were recorded. Patients can normally be mobilized the next day, avoiding excessive cervical motion, under neck collar protection. Car driving is allowed after one week, and the patient may go back to his job at one month. Follow-up plain $\mathrm{x}$-rays were performed on the first postoperative day. Periodic dynamic $\mathrm{x}$-rays were done on outpatient bases at 1 , 3,6 , and 12 months after surgery.

Data collected included VAS pain scores, pain medication intake, and functional abilities, including changes in performance levels of activities of daily living. At each evaluation, patients were asked to quantify their overall pain using a VAS pain score ranging from 0 to 10 . Patients were also surveyed in regards to their use of pain killers. Pain medication intake use was considered to be reduced if a patient reported complete cessation of intake or a daily reduction of $50 \%$ or more. Patients' functional status was quantified by patients' self-reports of ability to perform activities of daily living such as bathing, functional mobility, dressing, etc.

Successful outcomes were defined as residual mobility (flexion, extension) at the fusion level, preserved disc height, and no trabecular bridge formation at the anterior and/or posterior cortex of the involved vertebrae.

\section{RESULTS}

Our study showed that the procedure was safe and easy. There were no major complications.

The levels affected, and hence the number of DCI implants per level, were 3 at $\mathrm{C} 3-4,3$ at $\mathrm{C} 4-5,8$ at $\mathrm{C} 5-6$, and 1 at C6-7 (Fig. 1). The most common DCI prosthesis used in this study was the $6 \mathrm{M}$ size with a width of $12 \mathrm{~mm}$, a depth of $12 \mathrm{~mm}$, and a height of $9 \mathrm{~mm}$.

As no bone graft was required, we could save an average of 45 minutes compared to the traditional fusion procedure. Estimated blood loss ranged from $35 \mathrm{~mL}$ to $125 \mathrm{~mL}$, with an average of $75 \mathrm{~mL}$. This small estimated blood loss may also be attributed to preservation of the end plates. Hospital stay was minimal, ranging from 1 to 3 days with an average of 1.5 days. Hospital stay was short; most patients $(66.7 \%$, $10 / 15)$ were discharged within 2 days after surgery, $(20 \%$, $3 / 15)$ within 36 hours, and $(13.3 \%, 2 / 15)$ within 3 days.

\section{CLINICAL OUTCOME}

Postoperative follow-up varied from 7 to 24 months (mean, 12 months). Satisfactory results for neck and radicular pain were achieved by the first postoperative day and deficits had almost cleared by 3 months. Most patients $(86.7 \%, 13 / 15)$ lost their neck pain, and most of those presenting with radiculopathy $(86.7 \%, 13 / 15)$ showed dramatic improvement by the first day after surgery. Patients with myelopathy $(40 \%, 6 / 15)$, however, demonstrated more varied recovery from motor deficits and parasthesias. Motor defecits showed good recovery in 3 of the 6 patients (50\%), two $(33.3 \%)$ showed moderate improvement, and one (16.7\%) showed a little improvement, with a considerable persistent cord signal. Parasthesias showed good recovery in 3 of the 6 patients $(50 \%)$, the other 3 patients $(50 \%)$ showed a little improvement, with a persistence of cord signal. No patient underwent revision. Satisfactory symptomatic relief and good radiologic results were the usual findings.

There were no intraoperative or postoperative complications related to the procedure or the implant, and no dislodgement or failure. One patient had transient postoperative swallowing difficulty and another with mild hoarseness, but $\mathrm{x}$-rays showed that the DCI implants were in a good position. Both symptoms resolved by 1 month after surgery. One patient developed remote spondylodiscitis 3 levels (C6-7) below the operative site (C3-4), 2.5 month postoperatively. That patient was treated conservatively and resolved in 3 months.

\section{RADIOLOGICAL OUTCOME}

There was radiologic evidence of ideal DCI implant position in all patients. Dynamic motion (flexion, extension) was maintained at the operated level. The controlled mobility appeared to be preserved as visible motion on postoperative 


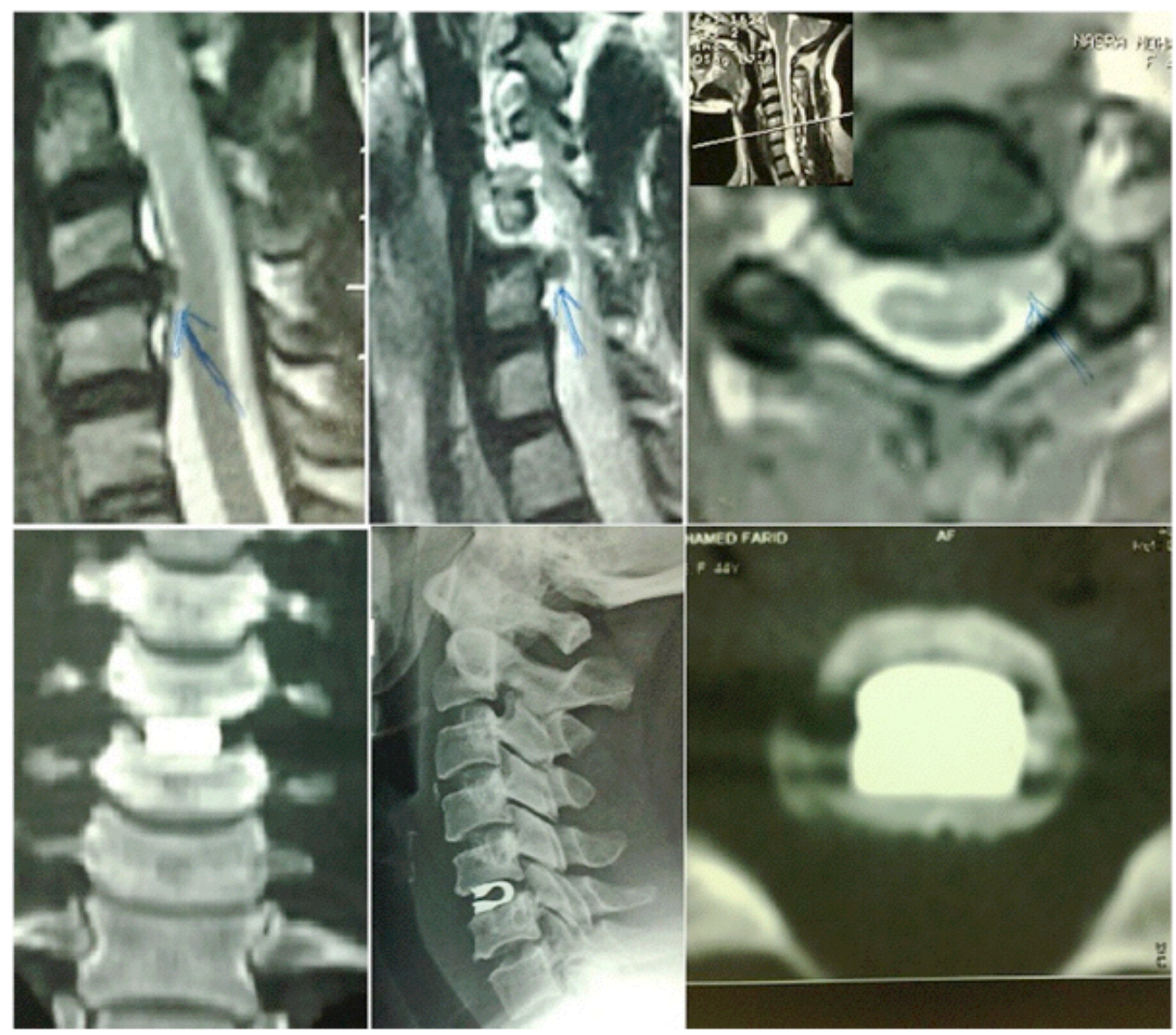

Fig. (2). A preoperative MRI showing C5,6 posterolateral disc protrusion, with postoperative lateral X-ray and 3D CT cervical spine showing the proper position of the DCI implant.

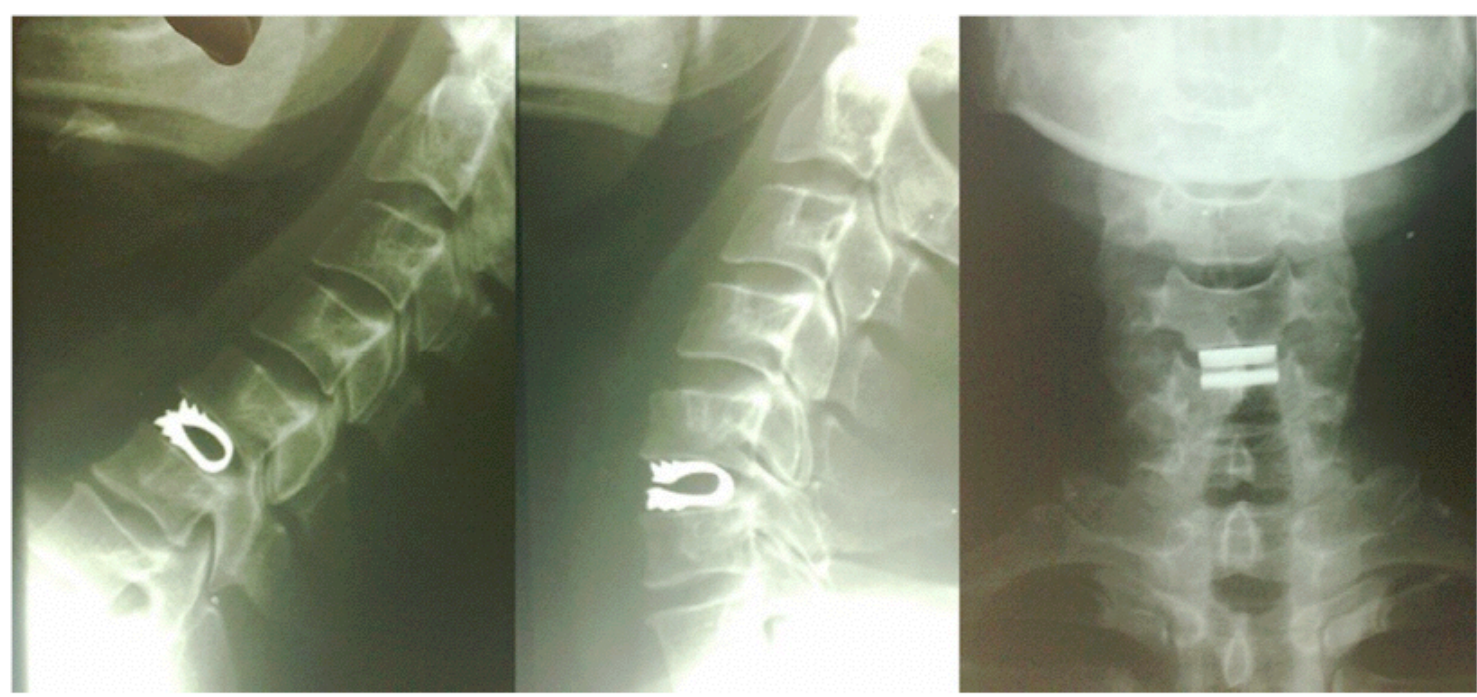

Fig. (3). Dynamic X-rays showing C5,6 preserved dynamic motion of the DCI implant I year postoperatively.

flexion and extension dynamic views; in which motion is definitely preserved in flexion and extension postoperatively (Fig. 3). Preserved disc height was apparent in all cases, with no implant subsidence into the adjacent end plate \& vertebral bodies in any case. No postoperative heterotopic fusions were reported till now. No other implant related failure, or complications were reported. Inadequate rigidity or unrecognized implant fracture was never encountered. Moreover, kyphosis was not the outcome in our cases. Use of DCI im- plants has been shown to assist with maintenance of postoperative lordosis. No revision surgery was needed during the whole study period.

\section{DISCUSSION}

Anterior cervical discectomy and fusion is the widely accepted approach for treatment of single level cervical disc disease. Interbody implant insertion following discectomy 

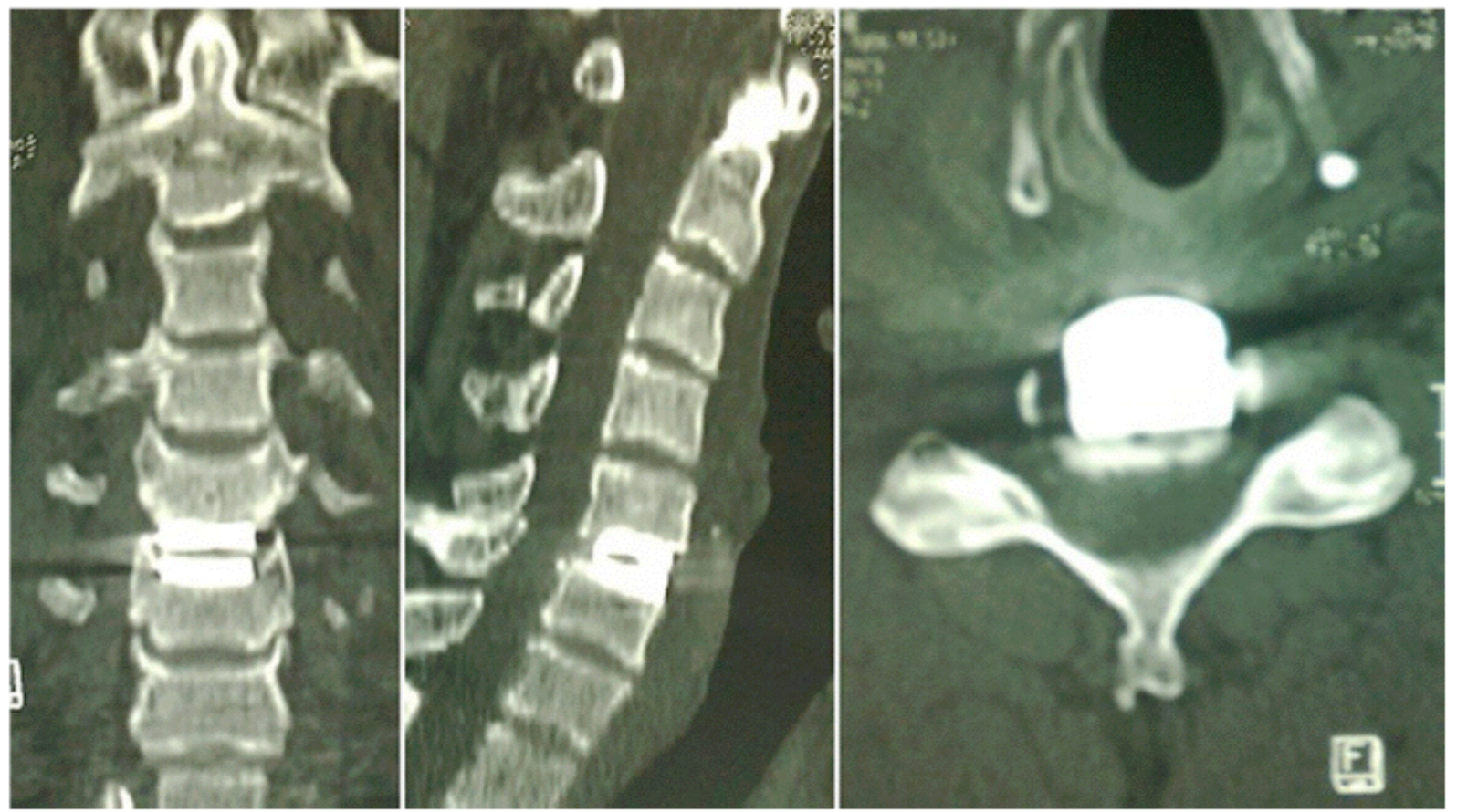

Fig. (4). A postoperative 3D CT of cervical spine showing C5,6 DCI implant in place after decompression.

for cervical DDD or HCD is needed to maintain sufficient disc height and neuroforamen volume to support the anterior column. Although different forms of static anterior cervical fusion works well at one level, long term studies have shown symptomatic adjacent level disease needing reoperations in $7 \%$ to $15 \%$ at 20 years follow-up [1, 10-19]. Preservation of dynamic controlled motion of the affected segment is indicated to delay fusion as long as possible. So, the demand for a better solution beyond static arthrodesis universally increased, and total disc replacement (TDR, arthroplasty) trials started to show in spine practice; aiming at restoring and maintaining the motion, segmental anatomy and function, while successfully treating the patient's symptoms. Heterotopic ossifications \& implant-related complications of the TDR itself made the procedure under continuous evaluations. Many types and forms of TDR implants were introduced in the market; none of them fulfill all the criteria of the ideal TDR prosthesis [8, 20-29]. So, the need for an intermediate solution between static fusion \& TDR rapidly increases. If the interbody implant can maintain a controlled movement in the affected motion segment, results are supposed to be better and adjacent level disease secondary to fusions is supposed to be delayed. The DCI implant is theoretically supposed to do that target.

The indications for DCI implantation in this study included: cervical DDD and/or HCD with discogenic neck pain, arm/shoulder radiating pain, or myelopathy; and involvement of discs between $\mathrm{C} 3$ and $\mathrm{C} 7$ at one level. We do not recommend that the DCI be implanted in an active infection site, in high grade spondylolisthesis or retrolisthesis $(>5$ $\mathrm{mm}$ ), in systemic illness or malignancy, or in severe osteoporosis. Although multilevel implantation can be done, we only used a single-level procedure in this study.

The basic concept of the interbody implant is to maintain a distraction-compression mechanism and so avoid possible collapse of the disc height. This is achieved using the special titanium-alloy DCI used in this study, which is biocompatible, available in various sizes, and provided with different foot prints. The U-shapped body provides support and has tooth-like serrations that resist expulsion or retropulsion of the implant when placed into the intervertebral space. With the endplate left intact, osteogenesis and bone fusion are inhibited and no further heterotopic fusions are supposed to occur $[7,11,14,20,24,30-33]$. Since the device is autostabilized and does not slip, further immobilization by external collar stabilization is not usually indicated. However, we routinely used external collar stabilization in the early postoperative weeks as a kind of temporary external support. The DCI implant therefore has several advantages: it corrects biomechanical kyphotic deformity and maintains anatomic lordosis and sagittal balance; it prevents further facet joint dislocation and widens the neuroforamen; it offers immediate stability and stiffness for loading-stress balance; it provides a proper environment for a controlled maintained segmental motion; it limits morbidity and operative complications; and it needs no auxiliary external fixation. The DCI implantation technique is quite similar to classic ACDF. Slight neck extension is essential to restore postoperative lordosis. The appropriate DCI can be selected with a template during surgery. Emphasis is on intervertebral distraction \& endplate preservation to allow good DCI impaction and prevent further subsidence. More emphasis is on preservation of anterior steophytes and nonviolation of the bony endplate to prevent heterotopic ossification [9].

Estimated blood loss ranged from $35 \mathrm{~mL}$ to $125 \mathrm{~mL}$, with an average of $75 \mathrm{~mL}$. Hospital stay was minimal, ranging from 1 to 3 days with an average of 1.5 days. As no iliac bone graft was required, we could save an average of 45 minutes compared to the traditional fusion procedure.

Our preliminary results were satisfactory both clinically and radiologically. Neck pain and radicular pain resolved quickly. Motor deficits improved more slowly during hospi- 

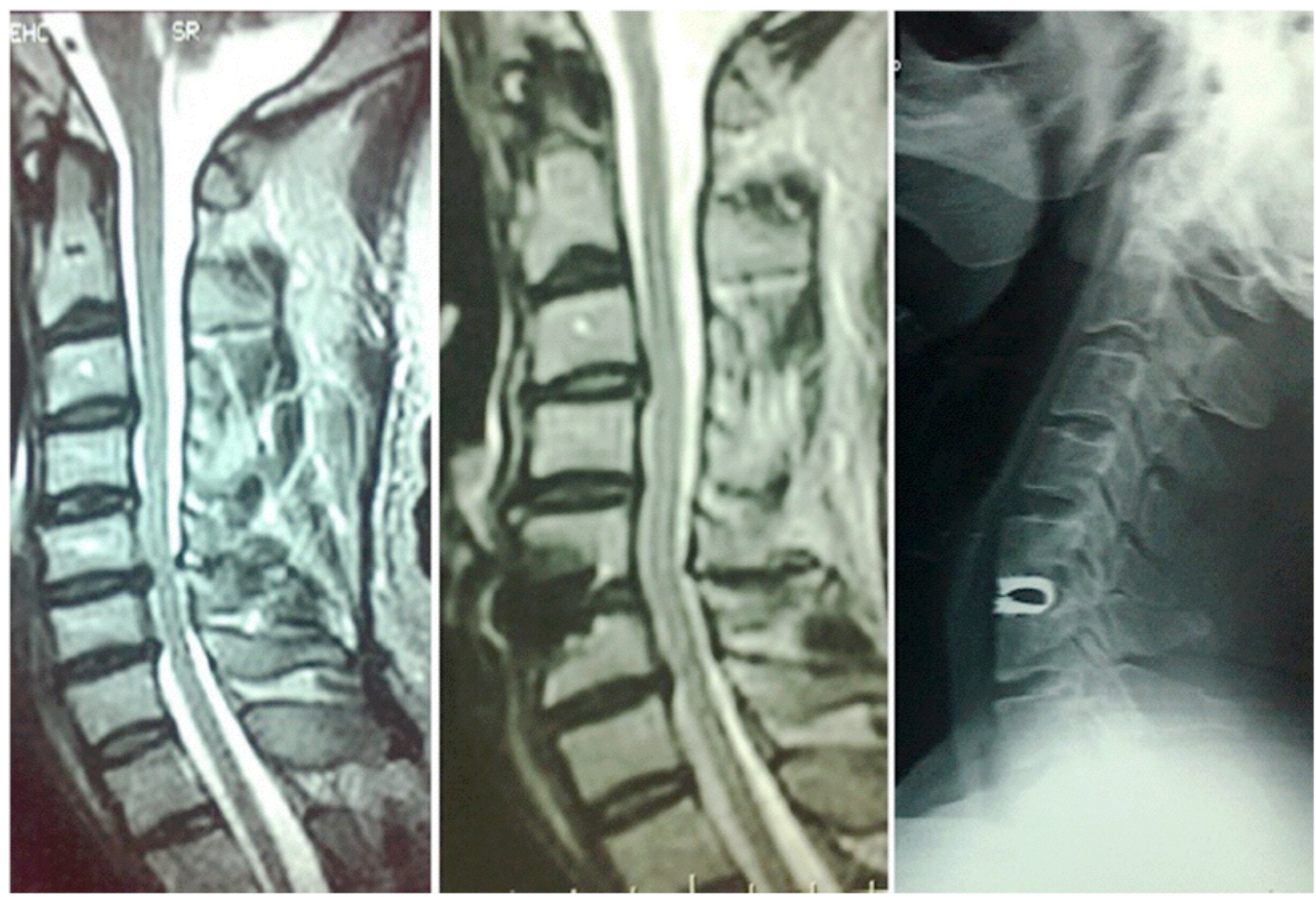

Fig. (5). A preoperative MRI showing C5,6 disc protrusion, with postoperative lateral X-ray and MRI images showing the DCI implant in place after decompression.
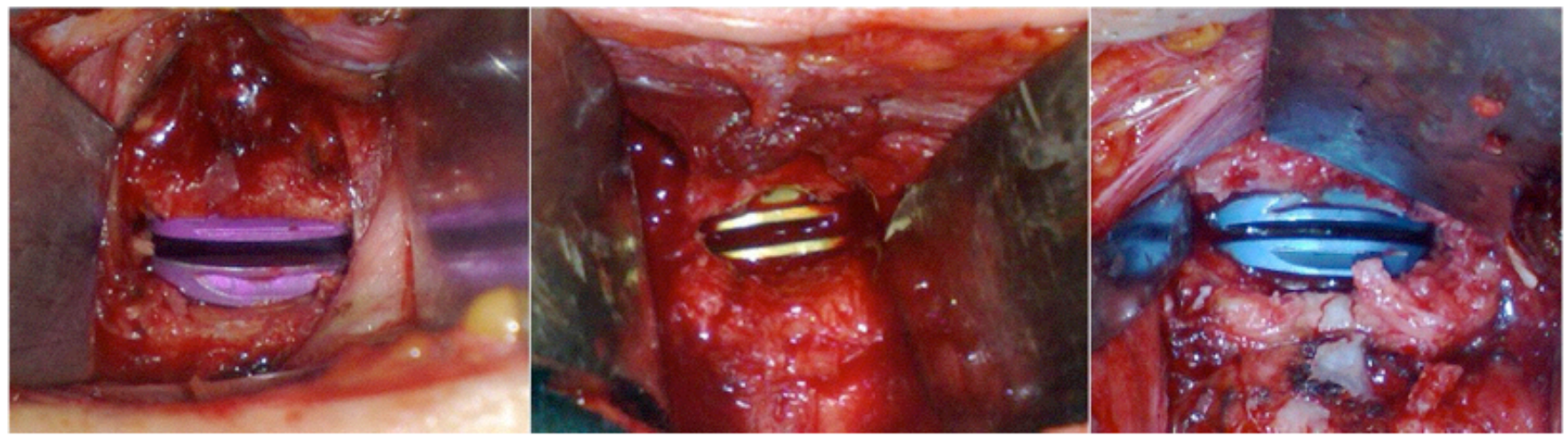

Fig. (6). Intraoperative views of operative field showing different sizes of the DCI implant in place.

talization and follow-up. Since no iliac bone harvesting procedure was needed, our procedure saved an average of 45 minutes of operative time and kept blood loss as low as an average of $75 \mathrm{~mL}$. Also, there were almost no complaints of postoperative wound pain or discomfort from all patients. Hospital stay was short; $66.7 \%$ patients were discharged within 2 days after surgery. They were able to return to work with almost complete relief of neck pain and radiculopathy and improved motor deficit. In our patients, we never encountered dural tear or CSF leakage, nerve damage after surgical trauma, discomfort due to the presence of the device, implant-related complications, or allergic reaction, bending or fracture of the implant, or decrease in bone density due to stress shielding. Over-sized DCI can never be selected because the tester would show the big ability to retropulse. So, in expert hands, it can never be chosen. No interbody fusion was established \& dynamic motion was maintained on lateral dynamic x-rays at 6 months and 1 year postoperatively.

Although controversial, there are data suggesting that the use of metal instrumentation in single-level anterior cervical fusion increases arthrodesis rates, the absence of arthrodesis, as targeted, was successful. Moreover, kyphosis, which is biomechanically unfavorable and may be associated with increased adjacent segment degeneration, mechanical neck pain, and neurological deficit, was not the outcome in our cases. Use of titanium implants has been shown to assist with maintenance of postoperative lordosis compared with noninstrumented fusions [2, 4, 5, 13, 18, 34-39]. Inadequate 
rigidity or unrecognized implant fracture was never encountered.

There are limited data in the literature on the use of this type of implant. The few reported results with use of DCI implant coincide with our results, that its use appears good \& safe, demonstrating preservation of controlled mobility in the treated level with no postoperative kyphosis. As previously indicated, in single level ACDF, use of DCI implant was associated with improved clinical \& radiological outcomes. Future studies will be required to address its long-term effects.

\section{CONCLUSION}

Disc replacement with DCI is a new strategy, in between ACDF \& ADR. It is an intermediate solution in the spectrum of management strategies of cervical disc diseases. The changes made in the new larger foodprint shape of the new generation of DCI is said to decrease the rate of fusion. Delay fusion as long as possible is expected to prevent of ALD, as the cervical spine has time to adapt to the changed biomechanics. The DCI ${ }^{\mathrm{TM}}$ implant is a fascinating alternative to total disc prosthesis with wider indications because of restriction of rotation which means no major concern with (facet) arthropathy, a serious problem of any arthroplasty with total disc replacements. In summary, treating single level cervical disc disease with the DCITM implant is a safe and easy procedure. Immediate dynamic stability with good clinical response and no implant-related morbidity or complications are the main advantages of this implant.

\section{CONFLICT OF INTEREST}

The authors confirm that this article content has no conflicts of interest.

\section{ACKNOWLEDGEMENT}

Declared none.

\section{REFERENCES}

[1] Gore DR, Sepic SB. Anterior discectomy and fusion for painful cervical disc disease: a report of 50 patients with an average follow-up of 21 years. Spine 1998; 23(19): 2047-51.

[2] Nasca RJ. Cervical radiculopathy: Current diagnostic and treatment options. J Surg Orthop Adv 2009; 18(1): 13-8.

[3] Odem GL, Finney W, Woodhall B. Cervical disk lesions. JAMA 1958; 16: 23-8.

[4] White AA 3rd, Southwick WO, Deponte RJ, Gainor JW, Hardy R. Relief of pain by anterior cervical spinal fusion for spondylosis. J Bone Joint Surg Am 1973; 55: 525-34.

[5] Smith GW, Robinson RA. The treatment of certain cervical spine disorders by anterior removal of the intervertebral disc and interbody fusion. J Bone Joint Surg (Am) 1958; 40 -A(3): 607-24.

[6] Stauffer RN, Coventry MB. Anterior interbody lumbar fusion. Analysis of Mayo Clinic series. J Bone Joint Surg Am 1972; 54A: 756-68.

[7] Dennis S, Watkins R, Landaker S, Dillin W, Springer D. Comparison of disc space heights after anterior lumbar interbody fusion. Spine 1989; 14: 876-8.

[8] Matgé G. Cervical cage fusion with 5 different implants: 250 cases. Acta Neurochir 2002; 44: 539-50.

[9] Matgé G. Dynamic Cervical Implant (DCI): Alternative between Cage Fusion and Total Disc Replacement to Preserve Motion and Prevent Adjacent Degeneration (2011 in preparation).
[10] Baba H, Furusawa N, Imura S, Kawahara N, Tsuchiya H, Tomita $\mathrm{K}$. Late radiographic findings after anterior cervical fusion for spondylotic myeloradiculopathy. Spine 1993; 18(15): 2167-73.

[11] Connolly PJ, Esses SI, Kostuik JP. Anterior cervical fusion: outcome analysis of patients fused with and without anterior cervical plates. J Spinal Disord 1996; 9: 202-6.

[12] Dmitriev AE, Cunningham BW, Hu N, Sell G, Vigna F, McAfee PC. Adjacent level intradiscal pressure and segmental kinematics following a cervical total disc arthroplasty: an in vitro human cadaveric model. Spine (Phila Pa 1976) 2005; 30(10): 1165-72.

[13] Goffin J, Geusens E, Vantomme N, et al. Long-term follow-up after interbody fusion of the cervical spine. J Spinal Disord Tech 2004; 17(2): 79-85.

[14] Hilibrand AS, Carlson GD, Palumbo MA, Jones PK, Bohlman HH. Radiculopathy and myelopathy at segments adjacent to the site of a previous anterior cervical arthrodesis. J Bone Joint Surg (Am) 1999; 81(4): 519-28.

[15] Kasimatis GB, Michopoulou S, Boniatis I, Dimopoulos P, Panayiotakis G, Panagiotopoulos E. The impact of fusion on adjacent levels in cervical spine injuries: Is it really important? Clin Neurol Neurosurg 2009; 111(10): 816-24.

[16] Kulkarmi V, Rajshekhar V, Raghuram L. Accelerated spondylotic changes adjacent to the fused segment following central cervical corpectomy MRI study evidence. J Neurosurg 2004; 100 (1 Suppl Spine): $2-6$.

[17] Rihn JA, Lawrence J, Gates C, Harris E, Hilibrand AS. Adjacent segment disease after cervical spine fusion. Instr Course Lect 2009; 58: 747-56.

[18] Sugawara T, Itoh Y, Hirano Y, Higashiyama N, Mizoi K. Long term outcome and adjacent disc degeneration after anterior cervical discectomy and fusion with titanium cylindrical cages. Acta Neurochir (Wien) 2009; 151(4): 303-9.

[19] Yang JY, Song HS, Lee M, Bohlman HH, Riew KD. Adjacent level ossification development after anterior cervical fusion without plate fixation. Spine 2009; 34 (15): 30-3.

[20] Bagby GW. Arthrodesis by the distraction-compression method using a stainless steel implant. Orthopedics 1988; 11: 931-44.

[21] Bartels R, Donk R. Fusion around cervical disc prosthesis: case report. Neurosurgery 2005; 57(1): 194.

[22] Bertagnoli R, Yue JJ, Pfeiffer F, et al. Early results after ProDisc-C cervical disc replacement. J Neurosurg Spine 2005; 2(4): 403-410.

[23] Heller JG, Sasso RC, Papadopoulos SM, et al. Comparison of BRYAN cervical disc arthroplasty with anterior cervical decompression and fusion: Clinical and radiographic results of a randomized, controlled, clinical trial. Spine 2009; 34(2): 101-7.

[24] Kim SW, Shin JH, Arbatin JJ, Park MS, Chung YK, McAfee PC. Effects of a cervical disc prosthesis on maintaining sagittal alignment of the functional spinal unit and overall sagittal balance of the cervical spine. Eur Spine J 2008; 17(1): 20-9.

[25] Mummaneni PV, Burkus JK, Haid RW, Traynelis VC, Zdeblick TA. Clinical and radiographic analysis of cervical disc arthroplasty compared with allograft fusion: a randomized controlled clinical trial. J Neurosurg Spine 2007; 6(3): 198-209.

[26] Murrey D, Janssen M, Delamarter R, et al. Results of the prospective, randomized, controlled multicenter Food and Drug Administration investigational device exemption study of the ProDisc-C total disc replacement versus anterior discectomy and fusion for the treatment of 1-level symptomatic cervical disc disease. Spine J 2009; 9(4): 275-86.

[27] Parkinson JF, Sekhon LH. Cervical arthroplasty complicated by delayed spontaneous fusion. Case report. J Neurosurg Spine 2005; 2(3): 377-380.

[28] Phillips FM, Allen TR, Regan JJ, et al. Cervical disc replacement in patients with and without previous adjacent level fusion surgery: a prospective study. Spine (Phila Pa 1976) 2009; 34(6) :556-65.

[29] Sasso RC, Smucker JD, Hacker RJ, Heller JG. Clinical outcomes of BRYAN cervical disc arthroplasty: a prospective, randomized, controlled,multicenter trial with 24-month follow-up. J Spinal Disord Tech 2007; 20(7): 481-91.

[30] De Bowes RM, Grant BD, Bagby GW, Butts MK. Cervical vertebral interbody fusion in the horse: a comparative study of bovine xenografts and autografts supported by stainless steel baskets. Am J Vet Res 1984; 45: 191-9.

[31] Lin CN, Wu YC, Wang NP. Interbody fusion cage. Taiwan Med J 2002; 45: 256-61. 
[32] Majd ME, Vadhva M, Holt RT. Anterior cervical reconstruction using titanium cages with anterior plating. Spine 1999; 24: 160410 .

[33] Martins AN. Anterior cervical discectomy with and without interbody graft. J Neurosurg 1976; 44: 290-5.

[34] Benini A, Krayenbuhl H, Bruder R. Anterior cervical discectomy without fusion: microsurgical technique. Acta Neurochir (Wien) 1982; 61: 105-10.

[35] Matge G, Leclercq TA. Rationale for interbody fusion with threaded titanium cages at cervical and lumbar levels. Results on 357 cases. Acta Neurochir (Wien) 2000; 142: 425-34.
[36] McAfee PC. Interbody fusion cage in reconstruction operation on the spine. J Bone Joint Surg Am 1999; 81A: 859-81.

[37] Whitecloud TS, Ricciardi JE, Werner JG. Bone graft, hardware, and halo fixator related problems. In: Clarke CR, ed. The Cervical Spine, 3rd ed. Philadelphia: Lippincott-Raven, 903-15, 1998.

[38] Wigfield CC, Nelson RJ. Nonautologous interbody fusion materials in cervical spine surgery: how strong is the evidence to justify their use? Spine 2001; 26: 687-94.

[39] Wilson D, Campbell D. Anterior cervical discectomy without bone graft. J Neurosurg 1977; 47: 551-5.

Received: December 27, 2013

(C) Mohamed M. Mohi Eldin; Licensee Bentham Open.

This is an open access article licensed under the terms of the Creative Commons Attribution Non-Commercial License (http://creativecommons.org/licenses/bync/3.0/), which permits unrestricted, non-commercial use, distribution and reproduction in any medium, provided the work is properly cited. 